1 V. J. Pope and C. S. Gibson, F. Chem. Soc., 1907, 91, 2061

2 B. Armer and H. Schmidbaur, Angew. Chem., Internat. Ed. En., 1970, 9, (2), 101

3 H. Gilman and L. A. Woods, F. Am. Chem. Soc., 1948, 70, (2), 550

4 G. E. Coates and C. Parkin, F. Chem. Soc., 1963, 421

5 A. Tamaki and J. K. Kochi, F. Chem. Soc., Dalton Trans., 1973, (23), 2620

6 G. W. Rice and R. S. Tobias, Inorg. Chem., 1976, 15, (2), 489

7 R. Usón, A. Laguna and J. Vicente, F. Chem. Soc., Chem. Commun., 1976, (10), 353

8 H. Schmidbaur, Accounts Chem. Res., 1975, 8, (2), 62

9 S. Komiya, T. A. Albright, R. Hoffman and J. K. Kochi, F. Am. Chem. Soc., 1976, 98, (23), 7255

10 A. Tamaki and J. K. Kochi, f. Organometal. Chem., 1973, 61, 441

11 A. Johnson and R. J. Puddephatt, f. Chem. Soc. Dalton Trans., 1976, (14), 1360

12 A. Tamaki and J. K. Kochi, f. Organometal. Chem., 1974, 64, (3), 411

13 A. Johnson and R. J. Puddephatt, f. Organometal. Chem., 1975, 85, (1), 115

14 A. Johnson, R. J. Puddephatt and J. L. Quirk, $\mathcal{F}$. Chem Soc., Chem. Commun, 1972, (16), 938
15 C. M. Mitchell and F. G. A. Stone, f. Chem. Soc., Dalton Trans., 1972, (1), 102

16 J. A. J. Jarvis, A. Johnson and R. J. Puddephatt, $\mathcal{F}$. Chem. Soc., Chem. Commun., 1973, (11), 373

17 S. Komiya and J. K. Kochi, Ұ. Am. Chem. Soc., 1976, 98, (24), 7599

18 B. J. Gregory and C. K. Ingold, F. Chem. Soc. B, 1969, (3), 276

19 R. J. Puddephatt and P. J. Thompson, F. Chem. Soc. Dalton Trans., 1975, (18), 1810

20 A. Johnson and R. J. Puddephatt, F. Chem. Soc., Dalton Trans., 1975, (2), 115

21 R. J. Puddephatt and P. J. Thompson, $\mathcal{F}$. Organometal. Chem., 1976, 117, (4), 395

22 G. W. Rice and R. S. Tobias, f. Organometal. Chem., 1975, 86, (2), C37

23 R. Kaptein, P. W. N. M. van Leeuwen and R. Huis, 7. Chem. Soc., Chem. Commun., 1975, (14), 568

24 P. W. N. M. van Leeuwen, R. Kaptein, R. Huis and C. F. Roobeek, F. Organometal. Chem., 1976, 104, (3), C44

25 G. Minghetti, L. Baratto and F. Bonati, f. Organometal. Chem., 1975, 102, (3), 397

26 J. E. Parks and A. L. Balch, F. Organometal. Chem., 1974, 71, (3), 453

27 J. A. McCleverty and M. M. M. da Mota, f. Chem. Soc., Dalton Trans., 1973, (23), 2571

\title{
Gold and Its Alloys in Dentistry
}

\section{A REVIEW OF THEIR PROPERTIES AND APPLICATIONS}

In a recent International Metallurgical Reviewpublished by the Metals Society, London, as Review 125-a comprehensive survey is given of the metals and alloys used as restorative materials in dentistry. The authors, Dr J. F. Bates of the Welsh National School of Medicine, Dental School, Cardiff, and Dr A. G. Knapton of the Johnson Matthey Research Centre, Reading, consider the metallic materials used both for restorations fixed in the mouth and for removable prostheses, and a considerable part of the review relates to gold and its alloys, which find most use in the first application.

Among the essential properties required by all materials to be used for any dental restorative work are high resistance to corrosion and compatibility with both hard and soft tissues. Gold, which does not collect plaque on polished surfaces as readily as other materials, amply satisfies these criteria and has been used in dentistry for over 2,500 years. The other necessary properties depend to a considerable extent on the application the material is to be used for, and many of the requirements are unique to dentistry.

Dental fillings are the most common type of fixed restorative and the metallic filling employed to fill cavities include pure gold which, when well made, is regarded as the most serviceable type of restoration.

An alternative to packing filling material into a cavity is to cement a dental casting into the tooth Such castings are made to a high degree of accuracy by the lost wax process and a variety of gold alloys, which are classified into four types according to mechanical strength or hardness, are used for this purpose. The composition of these materials is based largely on the gold-silver-copper system with varying additions of other elements including zinc and the platinum metals. The type of casting alloy selected depends largely on the stresses the casting is likely to be subjected to, the relatively soft Type I golds being used where minimum stresses occur while at the other end of the range the extra hard Type IV are used for thin sections which must withstand high masticatory forces. The properties of these Type IV golds also enable them to be used for certain removable appliances. The review ably describes the functions of the various components of the gold alloys; their composition and mechanical properties are tabulated and appropriate phase diagrams given.

One approach to the search for better materials for dentistry has been the development of composites consisting of an accurate gold casting which is enamelled with porcelain. This can produce a restoration which is indistinguishable from the natural tooth and strong enough to withstand the forces involved. The success of this process, which is basically one of vitreous enamelling, depends on a number of requirements which are described and discussed.

Because many dental appliances are too large to be made as a single casting it is frequently necessary to join smaller pieces together and gold solders are generally used for this purpose. Once again these are based on the gold-silver-copper system with appropriate additions to lower the melting point.

The high cost of gold has undoubtedly stimulated considerable effort to find cheaper alternative materials but nevertheless it is still very widely used. With the technical properties of gold so eminently suitable for applications in restorative dentistry, and its appearance so aesthetically pleasing, any further significant replacement by base metals seems unlikely in the immediate future. 